\title{
Influence of chronic kidney disease on early clinical outcomes after off-pump coronary artery bypass grafting
}

\author{
Xihui Li* ${ }^{*}$, Siyu Zhang and Feng Xiao
}

\begin{abstract}
Background: Patients with chronic kidney disease (CKD) have a high incidence of coronary heart disease, which is the leading cause of death in these patients. Coronary artery bypass grafting (CABG) significantly increases shortterm mortality and decreases long-term mortality in patients with CKD compared with percutaneous coronary intervention (PCI). The effect of CKD on the early outcomes of off-pump CABG is not well-studied. We aimed to investigate the effect of CKD on early postoperative mortality and complications following off-pump CABG.

Methods: We retrospectively analyzed preoperative baseline and surgery data for 1173 patients undergoing offpump CABG from January 2010 to December 2017 in the Department of Cardiac Surgery, Peking University First Hospital. Outpatient follow-up was performed until 30 days postoperatively. Patients with estimated glomerular filtration rates calculated according to the Chronic Kidney Disease Epidemiology Collaboration equation of $\geq 60 \mathrm{~mL} /$ $\mathrm{min} / 1.73 \mathrm{~m}^{2}$ were assigned to the normal renal function group (normal group, $n=924$ ), and those with a rate $<60$ $\mathrm{mL} / \mathrm{min} / 1.73 \mathrm{~m}^{2}$ were assigned to the CKD group (CKD group, $n=249$ ).

Results: Patients in the CKD group were seriously ill with multiple complications, and postoperative 30-day mortality and complication rates were significantly higher than those in the normal group. In the logistic regression analysis, after correcting for common confounding factors, namely sex, age, and left ventricular ejection fraction, preoperative CKD was a risk factor for postoperative acute kidney injury, perioperative myocardial infarction, gastrointestinal bleeding, secondary tracheal intubation, stroke, chest wound infection, prolonged mechanical ventilation ( $\geq 24 \mathrm{~h}$ ), prolonged intensive care unit stay ( $\geq 72 \mathrm{~h}$ ), prolonged length of stay ( $\geq 14 \mathrm{~d})$, dialysis requirement, and postoperative death within 30 days.

Conclusions: Patients with CKD had more preoperative complications, and their postoperative 30-day mortality and complication rates after off-pump CABG were significantly higher than those of patients with normal renal function. For CABG patients with CKD, the risk of surgery should be assessed carefully, and comprehensive measures should be taken to strengthen perioperative management, with an aim to reduce complications and mortality and improve surgical outcomes.
\end{abstract}

Keywords: Chronic kidney disease, Coronary artery bypass grafting, Off-pump

* Correspondence: heart2000@163.com

Department of Cardiac Surgery, Peking University First Hospital, 8 Xishiku

Street, Beijing 100034, People's Republic of China

C C The Author(s). 2020 Open Access This article is licensed under a Creative Commons Attribution 4.0 International License, which permits use, sharing, adaptation, distribution and reproduction in any medium or format, as long as you give appropriate credit to the original author(s) and the source, provide a link to the Creative Commons licence, and indicate if changes were made. The images or other third party material in this article are included in the article's Creative Commons licence, unless indicated otherwise in a credit line to the material. If material is not included in the article's Creative Commons licence and your intended use is not permitted by statutory regulation or exceeds the permitted use, you will need to obtain permission directly from the copyright holder. To view a copy of this licence, visit http://creativecommons.org/licenses/by/4.0/ The Creative Commons Public Domain Dedication waiver (http://creativecommons.org/publicdomain/zero/1.0/) applies to the data made available in this article, unless otherwise stated in a credit line to the data. 


\section{Background}

Patients with chronic kidney disease (CKD) have a high incidence of coronary heart disease [1], which is the leading cause of death in these patients. Concurrent CKD and percutaneous coronary intervention (PCI) or coronary artery bypass grafting (CABG) increases mortality in patients undergoing revascularization [2, 3]. However, CABG significantly increases short-term mortality and decreases longterm mortality in patients with CKD compared with PCI [4]. Currently, off-pump CABG is the main surgical procedure in mainland China, and accounts for approximately $95 \%$ of the total number of CABG procedures in our department. The effect of CKD on the early outcomes of off-pump CABG is not well-studied. We retrospectively studied the early outcomes of 1173 patients undergoing off-pump CABG from January 2010 to December 2017 in the Department of Cardiac Surgery, Peking University First Hospital.

\section{Methods}

\section{Study design and subjects}

Inclusion criteria: consecutive, first-time, off-pump CABG patients. Exclusion criteria: patients with preoperative acute renal insufficiency, preoperative dialysis dependence, and intraoperative transfer to extracorporeal circulation. We used the Chronic Kidney Disease Epidemiology Collaboration (CKD-EPI) equation to calculate estimated glomerular filtration rates (eGFR) [5]. Patients with eGFR $_{\text {CKD-EPI }} \geq 60 \mathrm{~mL} / \mathrm{min} / 1.73 \mathrm{~m}^{2}$ were assigned to the normal renal function group (normal group), and those with GFR $_{\text {CKD-EPI }}<60 \mathrm{~mL} / \mathrm{min} / 1.73 \mathrm{~m}^{2}$ were assigned to the CKD group. We collected data for patients during hospitalization and from their postoperative outpatient follow-up records within 30 days, for statistical analysis. The clinical observation outcomes were stroke, prolonged mechanical ventilation $(\geq 24 \mathrm{~h})$, reintubation, redo for bleeding, perioperative myocardial infarction (PMI), upper gastrointestinal bleeding (UGH), new atrial fibrillation, acute respiratory distress syndrome (ARDS), low cardiac output syndrome (LCOS), perioperative use of intra-aortic balloon pump (IABP), chest wound infection, acute kidney injury (AKI), prolonged intensive care unit (ICU) stay $(\geq$ $72 \mathrm{~h}$ ), prolonged length of stay ( $\geq 14 \mathrm{~d})$, dialysis replacement, and postoperative death within 30 days. PMI was defined as increased cardiac troponin I (CTNI) values to $>10$ times baseline values, or new pathological Q waves. ARDS was defined as partial pressure of arterial oxygen to fraction of inspired oxygen $\left(\mathrm{PaO}_{2} / \mathrm{FiO}_{2}\right) \leq 300 \mathrm{mmHg}$ and positive end-expiratory pressure (PEEP) or continuous positive airway pressure (CPAP) $\geq 5 \mathrm{cmH}_{2} \mathrm{O}$, and classic chest radiographic changes. LCOS was defined as cardiac index $<2.0 \mathrm{~L} / \mathrm{min} / \mathrm{m}^{2}$, with sufficient blood volume and systolic pressure $<90 \mathrm{mmHg}$. AKI was defined as a sudden decrease in renal function within $48 \mathrm{~h}$ after operation, absolute value of serum creatinine increased by $>26 \mu \mathrm{mol} / \mathrm{L}$, or serum creatinine increased by $>50 \%$ or urine volume decreased to $<0.5 \mathrm{~mL} / \mathrm{kg} / \mathrm{h}$ for more than $6 \mathrm{~h}$.

All patients were treated with routine tracheal inhalation and intravenous anesthesia, implantation of a Swan-Ganz floating catheter, median sternotomy, and off-pump coronary artery bypass grafting. The left internal mammary artery and/or great saphenous vein and/or non-dominant radial artery were used as graft vessels. The distal graft vessels were anastomosed with an Octopus tissue stabilizer (Medtronic, Inc., Minneapolis, MN, USA), and the proximal graft vessels were anastomosed with side wall forceps after partial aortic occlusion. If calcification of the ascending aorta was serious, proximal anastomosis was used to anastomose the proximal part of the graft vessel.

\section{Statistical analysis}

We used SPSS version 21.0 (IBM Corp., Armonk, NY, USA) to analyze the data, and the $X^{2}$ test or Fisher's exact test to compare the enumeration data between the two groups. Measurement data were analyzed using the $t$ test. We performed logistic regression to analyze the effect of preoperative renal function status on postoperative mortality and complications. Odds ratios (OR) and 95\% confidence intervals $(\mathrm{CI})$ were calculated after univariate regression analysis and after correcting for common confounding factors, such as sex, age, and left ventricular ejection fraction (LVEF). Two-sided $p<0.05$ was considered statistically significant.

\section{Results}

Preoperative patients' baseline clinical data are shown in Table 1. Female sex and advanced age, with hypertension, diabetes, lower LVEF, and lower hemoglobin level were more common in the CKD group $(p<0.001)$ compared with the normal group, as were preoperative stroke, atrial fibrillation, and lower albumin level $(p<0.05)$.

Surgery and follow-up data within 30 days are shown in Table 2. Complication rates in the CKD group and postoperative death within 30 days were significantly higher than those in the normal group. The results of the logistic regression analysis of the influence of preoperative renal function status on postoperative death and complications after CABG are shown in Table 3. Preoperative CKD was a risk factor for postoperative complications and postoperative 30-day all-cause mortality (OR: $5.309 ; p<0.001$ ). After correcting for the common confounding factors of sex, age, and LVEF, preoperative CKD was no longer a risk factor for LCOS (OR: $1.444 ; p=0.449$ ), perioperative IABP use (OR: 1.617; $p=0.054)$, postoperative new atrial fibrillation (OR: $1.244 ; p=0.240$ ), or prolonged mechanical ventilation time (OR: 1.248; $p=0.216$ ).

\section{Discussion}

An epidemiological survey in 2012 indicated that the incidence of CKD in China was $10.8 \%$, and that the 
Table 1 Preoperative patients' baseline clinical data between the two groups

\begin{tabular}{|c|c|c|c|c|}
\hline & Normal Group $(n=924)$ & CKD Group $(n=249)$ & $t / x^{2}$ & $P$ \\
\hline Age (ys) & $63.5 \pm 9.3$ & $69.8 \pm 9.2$ & 9.618 & $<0.001 \dagger$ \\
\hline Female sex & $228(24.7)$ & $117(47)$ & 47.035 & $<0.001+$ \\
\hline Hypertension & $607(65.7)$ & $208(83.5)$ & 29.444 & $<0.001+$ \\
\hline Diabetes & $353(38.2)$ & $130(52.2)$ & 15.884 & $<0.001+$ \\
\hline Stroke & $195(21.1)$ & $71(28.5)$ & 6.142 & $0.013+$ \\
\hline Hyperlipemia & $389(42.1)$ & $118(47.4)$ & 2.237 & 0.135 \\
\hline COPD & $25(2.7)$ & $8(3.2)$ & 0.185 & 0.667 \\
\hline AF & $40(4.3)$ & $21(8.4)$ & 6.704 & $0.01+$ \\
\hline Emergency & $18(1.9)$ & $7(2.8)$ & 0.701 & 0.403 \\
\hline \multicolumn{5}{|l|}{ Diseased coronary vessels } \\
\hline Triple & $602(65.1)$ & $155(62.3)$ & 1.569 & 0.210 \\
\hline Left main & $33(3.6)$ & $10(4.0)$ & 0.110 & 0.740 \\
\hline Left main + Triple & $217(23.5)$ & $70(28.1)$ & 2.246 & 0.134 \\
\hline Others (single or two) & $72(7.8)$ & $14(5.6)$ & 1.359 & 0.244 \\
\hline LVEF(\%) & $61.1 \pm 13.2$ & $57.4 \pm 13.2$ & 3.579 & $<0.001+$ \\
\hline Hemoglobin(g/L) & $135.0 \pm 15.4$ & $121.9 \pm 18.7$ & 10.216 & $<0.001+$ \\
\hline Albumin(g/L) & $40.1 \pm 13.8$ & $37.9 \pm 4.2$ & 2.484 & $0.013+$ \\
\hline
\end{tabular}

COPD Chronic obstructive pulmonary disease, AF Atrial fibrillation, LVEF Left ventricular ejection fraction †Significant difference

estimated number of existing CKD patients was 119.5 million [6]. The risk of coronary heart disease is significantly increased in patients with CKD. Inflammatory reactions, oxidative stress, impaired endothelial cell function, coronary artery calcification, hyperhomocysteinemia, immune suppression, and other mechanisms participate in accelerating the progression of atherosclerosis, which leads to a poor prognosis in this population. Coronary heart disease-related complications, including myocardial infarction and heart failure, are the main causes of death

Table 2 Surgery and follow-up data within 30 days between the two groups

\begin{tabular}{|c|c|c|c|c|}
\hline & Normal Group $(n=924)$ & CKD Group $(n=249)$ & $t / X^{2}$ & $P$ \\
\hline $\mathrm{AKI}$ & $135(14.6)$ & $59(23.7)$ & 11.727 & $<0.001 \dagger$ \\
\hline PMl & $165(17.9)$ & $55(22,1)$ & 2.305 & 0.129 \\
\hline UGH & $12(1.3)$ & $11(4.4)$ & - & $0.004+$ \\
\hline $\mathrm{AF}$ & $155(16.8)$ & $64(25.7)$ & 10.296 & $<0.001 \dagger$ \\
\hline LCOS & $63(6.8)$ & $32(12.9)$ & 9.719 & $0.002+$ \\
\hline $\mathrm{IABP}$ & $63(6.8)$ & $40(16.1)$ & 20.935 & $<0.001 \dagger$ \\
\hline Redo for bleeding & $10(1.1)$ & $4(1.6)$ & - & 0.512 \\
\hline Reintubation & $13(1.4)$ & $13(5.2)$ & 13.164 & $<0.001 \dagger$ \\
\hline ARDS & $93(10.1)$ & $35(14.1)$ & 3.152 & 0.076 \\
\hline Wound infection & $18(2.0)$ & $13(5.2)$ & 8.146 & $0.004+$ \\
\hline Stroke & $14(1.5)$ & $11(4.4)$ & 7.905 & $0.005+$ \\
\hline Ventilation time $\geq 24 \mathrm{~h}$ & $176(19.1)$ & $66(26.5)$ & 6.536 & $0.011+$ \\
\hline ICU stay $\geq 72 \mathrm{~h}$ & $273(29.6)$ & $111(44.6)$ & 20.031 & $<0.001 \dagger$ \\
\hline$L O S \geq 14 d$ & $345(37.3)$ & $147(59.0)$ & 37.924 & $<0.001 \dagger$ \\
\hline Dialysis replcement & $2(0.2)$ & $9(3.6)$ & - & $<0.001 \dagger$ \\
\hline Death & $8(0.9)$ & $11(4.4)$ & - & $<0.001 \dagger$ \\
\hline
\end{tabular}

AKI Acute kidney injury, PMI Perioperative myocardial infarction, UGH Upper gastrointestinal hemorrhage, AF Atrial fibrillation, $L C O S$ Low cardiac output syndrome, $I A B P$ Intra-aortic balloon pump, ARDS Acute respiratory distress syndrome, LOS Length of stay †Significant difference 
Table 3 Results of the logistic regression analysis

\begin{tabular}{|c|c|c|c|c|c|c|c|c|}
\hline & Unadjus & & & & Adjuste & & & \\
\hline & OR & $95 \%$ & $\mathrm{Cl}$ & $p$ & $\mathrm{OR}$ & $95 \%$ & $\mathrm{Cl}$ & $p$ \\
\hline$\overline{A K I}$ & 1.815 & 1.286 & 2.561 & $0.001+$ & 1.550 & 1.071 & 2.244 & $0.02+$ \\
\hline PMl & 1.304 & 0.925 & 1.839 & 0.130 & 1.237 & 0.856 & 1.789 & 0.257 \\
\hline UGH & 3.509 & 1.529 & 8.051 & $0.003+$ & 2.716 & 1.102 & 6.691 & $0.030+$ \\
\hline AF & 1.716 & 1.231 & 2.393 & $0.001 \dagger$ & 1.244 & 03864 & 1.789 & 0.240 \\
\hline LCOS & 2.025 & 1.290 & 3.178 & $0.002+$ & 1.444 & 0.877 & 2.378 & 0.149 \\
\hline IABP & 2.616 & 1.712 & 3.997 & $0.001+$ & 1.617 & 0.992 & 2.636 & 0.054 \\
\hline Redo for bleeding & 1.492 & 0.464 & 4.799 & 0.502 & 1.989 & 0.561 & 7.046 & 0.287 \\
\hline Reintubation & 3.860 & 1.766 & 8.438 & $0.001+$ & 2.514 & 1.074 & 5.885 & $0.034 \dagger$ \\
\hline ARDS & 1.456 & 0.960 & 2.209 & 0.077 & 1.152 & 0.736 & 1.802 & 0.537 \\
\hline Wound infection & 2.770 & 1.338 & 5.733 & $0.006+$ & 2.586 & 1.171 & 5.714 & $0.019+$ \\
\hline Stroke & 3.001 & 1.345 & 6.695 & $0.007 \dagger$ & 2.789 & 1.165 & 6.676 & 0.021 \\
\hline Ventilation $\geq 24 \mathrm{~h}$ & 1.527 & 1.102 & 2.115 & $0.011 \dagger$ & 1.248 & 0.879 & 1.773 & 0.216 \\
\hline$I C U \geq 72 \mathrm{~h}$ & 1.915 & 1.437 & 2.552 & $0.001+$ & 1.658 & 1.218 & 2.258 & $<0.001 \dagger$ \\
\hline$L O S \geq 14 d$ & 2.419 & 1.818 & 3.218 & $0.001+$ & 1.828 & 1.348 & 2.478 & $<0.001 \dagger$ \\
\hline Dialysis replacement & 17.287 & 3.711 & 80.538 & $0.001+$ & 23.153 & 4.534 & 118.238 & $<0.001 \dagger$ \\
\hline Death & 5.309 & 2.112 & 13.345 & $0.001+$ & 3.424 & 1.251 & 9.374 & $0.017 \dagger$ \\
\hline
\end{tabular}

AKI Acute kidney injury, PMI Perioperative myocardial infarction, UGH Upper gastrointestinal hemorrhage, AF Atrial fibrillation, LCOS Low cardiac output syndrome, IABP Intra-aortic balloon pump, ARDS Acute respiratory distress syndrome, LOS length of stay

†Significant difference

[7]. In patients with CKD, lipid metabolism disorders, mainly hypertriglyceridemia, are risk factors for complications related to coronary heart disease. This risk factor results in approximately $12 \%$ of people with stage 3 or more advanced CKD also having coronary heart disease, compared with 5\% of people with normal renal function [8]. Patients with CKD also often have associated bone mineral metabolism disorders such as hypocalcemia and hyperphosphatemia, as well as secondary hyperparathyroidism, which also accelerate systemic atherosclerosis and vascular calcification [9]. Currently, the number of patients with CKD in mainland China is very high, and many more patients with coronary heart disease will require $\mathrm{CABG}$ in the future.

For patients with CKD with severe coronary heart disease and not receiving dialysis, CABG significantly reduces mortality, reinfarction, and revascularization rates compared with PCI and drug therapy [10, 11]. For low-risk patients, CABG does not improve survival compared with PCI and oral medications, but significantly improves survival for high-risk patients. CABG increases the incidence of postoperative renal failure [12]. In a nonrandomized study prospectively analyzing patients' data, 2108 patients with CKD and with drug-eluting stents underwent PCI $(n=1165)$ and CABG ( $n=943)$, with a mean follow-up of 41.4 months. Although there were no significant differences in all-cause death, stroke, or myocardial infarction rates between the two groups, the revascularization rate was significantly higher in the PCI group (adjusted hazard ratio: 4.72; 95\% CI: $3.20-6.96 ; p<0.001$ ) [13]. A meta-analysis of 29,246 patients enrolled in 11 studies showed that CABG was associated with lower long-term all-cause mortality, lower cardiac mortality, lower incidence of myocardial infarction and revascularization, and fewer major cardiac and cerebrovascular adverse events compared with drug-eluting stents in revascularization for coronary heart disease in patients with multivessel disease and CKD [14]. For patients with type 2 diabetes, CKD and stable coronary heart disease, CABG and optimal drug therapy did not reduce the incidence of major cardiac and cerebrovascular adverse events, but significantly reduced the proportion of patients requiring revascularization [15]. Therefore, CABG has a significant advantage over PCI and drug therapy in patients with coronary heart disease and CKD.

CABG is the key to protecting renal function and improving postoperative survival rates in patients with CKD; however, whether to select off-pump or on-pump CABG is controversial. According to current research, off-pump CABG may have more advantages because it has a protective effect on renal function perioperatively in avoiding cardiopulmonary bypass, and reduces complications related to allogeneic blood transfusion, postoperative thoracotomy hemostasis, acute kidney injury, and respiratory problems [16]. However, in the CORONARY study, no significant difference in the effect of the two surgical procedures was seen regarding renal function at the 1-year follow-up, and off-pump CABG had no long-term renal protective effect [17]. Ueki et al. reviewed data from 38,051 patients undergoing CABG 
alone and assigned patients to separate groups according to renal function. The results showed that in the mild renal insufficiency group, there was no significant reduction in the risk of death from off-pump CABG compared with the on-pump CABG group. In the moderate to severe renal insufficiency group, compared with on-pump CABG, off-pump CABG significantly reduced surgical mortality and the risk of requiring postoperative dialysis, in patients with severe renal insufficiency [18].

Off-pump CABG is the main surgical method in our department. In this study, patients with CKD were mainly older women, and were more often complicated with hypertension, diabetes, stroke, atrial fibrillation, hypoproteinemia, anemia, and lower LVEF. Postoperative 30 -day mortality $(p<0.001)$ and complications in the CKD group were significantly higher than in the normal group in our study. Logistic regression analysis showed that preoperative CKD increased postoperative complications and postoperative 30-day mortality. After correcting for sex, age, and LVEF, preoperative CKD remained a risk factor for the following complications: AKI, gastrointestinal bleeding, secondary endotracheal intubation, stroke, chest wound infection, prolonged ICU stay, prolonged length of stay, dialysis replacement, and postoperative death within 30 days. Therefore, even with off-pump CABG, postoperative complications and 30-day mortality in patients with CKD remained significantly higher than in those with normal renal function.

Preoperative CKD and worse renal function is associated with increased hospital stay and costs. Creatinine clearance rates decreasing from $80 \mathrm{~mL} / \mathrm{min}$ to $60 \mathrm{~mL} /$ $\mathrm{min}, 40 \mathrm{~mL} / \mathrm{min}$, and $20 \mathrm{~mL} / \mathrm{min}$ result in total hospital expenses increasing by 10,20 , and $30 \%$, respectively; the incidence and mortality related to dialysis also increases [19]. Therefore, it is necessary to strengthen perioperative management and develop comprehensive strategies for high-risk patients, to improve prognosis and reduce complications and mortality. We suggest: 1 . Preoperative assessment of high-risk patients with CKD is conducive to rational allocation of medical resources and targeted prevention and management. More severe preoperative CKD is associated with higher surgical mortality. A retrospective analysis of 483,914 patients undergoing CABG alone showed that the operative mortality rate was $1.3 \%$ in patients with normal renal function and increased to $9.3 \%$ in those with severe renal insufficiency $\left(\mathrm{GFR}<30 \mathrm{~mL} / \mathrm{min} / 1.73 \mathrm{~m}^{2}\right)$ not on dialysis [20]. Conversely, for every $10 \mathrm{~mL} / \mathrm{min} / 1.73 \mathrm{~m}^{2}$ increase in eGFR, the risk of death decreases by $20 \%$ [21]. The use of the CKD-EPI equation to calculate eGFR for grouping patients according to CKD severity is also a good predictor of postoperative complications and mortality [22]. Charytan et al. suggested that factors such as repeat cardiac surgery, stroke, cardiogenic shock, emergency surgery, and composite valve surgery should be included in the preoperative risk assessment to identify high-risk patients for surgery; however, the specificity and sensitivity of these factors require verification [23]. 2. Active control of complications, such as controlling hypertension, correcting anemia, and rational treatment of peripheral artery disease is important. Patients with CKD have a high incidence of hypertension, which may lead to or result from CKD. Hypertension aggravates CKD, which then increases the difficulty of controlling hypertension [24]. Anemia is also a common manifestation with renal insufficiency, and renal dysfunction leads to decreased erythropoietin secretion and anemia. Both anemia and CKD can predict myocardial ischemia in patients with coronary heart disease; the severity of the anemia is associated with the degree of myocardial ischemia [25]. 3 . New targeted drug therapies such as small-dose human atrial natriuretic peptide injections perioperatively during on-pump CABG can improve perioperative cardiac and renal function and reduce the incidence of cardiac events and new dialysis requirement [26]. However, the role of human atrial natriuretic peptide injections in offpump CABG must be verified.

\section{Conclusion}

Patients with CKD have significantly more preoperative complications, and higher 30-day mortality and complication rates after off-pump CABG than patients with normal renal function. For patients with CKD scheduled for CABG, the risk of surgery should be assessed carefully, and comprehensive measures should be taken to strengthen perioperative management, with an aim to reduce complications and mortality and improve surgical outcomes.

\section{Acknowledgements \\ We thank Jane Charbonneau, DVM, from Liwen Bianji, Edanz Group China (www.liwenbianji.cn/ac), for editing the English text of a draft of this manuscript.}

\section{Authors' contributions}

Feng Xiao and Xihui Li performed the literature search; Xihui Li and Siyu Zhang performed the data collection. All authors read and approved the final manuscript.

\section{Funding \\ We received no funding for this study.}

Availability of data and materials

Please contact the corresponding author for data requests.

Ethics approval and consent to participate

This study was approved by the biomedical research ethics committee of Peking University First Hospital (approval No. 2018, scientific research 242), and the need for informed consent was waived.

Consent for publication

Not applicable.

Competing interests

The authors declare that they have no competing interests. 
Received: 28 May 2020 Accepted: 20 July 2020

Published online: 29 July 2020

\section{References}

1. Go AS, Chertow GM, Fan D, McCulloch CE, Hsu CY. Chronic kidney disease and the risks of death, cardiovascular events, and hospitalization. N Engl J Med. 2004:351(13):1296-305.

2. Mehta RL, Kellum JA, Shah SV, et al. Acute kidney injury network: report of an initiative to improve outcomes in acute kidney injury. Crit Care (London, England). 2007;11(2):R31.

3. Best PJ, Lennon $\mathrm{R}$, Ting $\mathrm{HH}$, et al. The impact of renal insufficiency on clinical outcomes in patients undergoing percutaneous coronary interventions. J Am Coll Cardiol. 2002:39(7):1113-9.

4. Kannan A, Poongkunran C, Medina R, Ramanujam V, Poongkunran M, Balamuthusamy S. Coronary revascularization in chronic and end-stage renal disease: a systematic review and meta-analysis. Am J Ther. 2016;23(1):e16-28.

5. Michels WM, Grootendorst DC, Verduijn M, Elliott EG, Dekker FW, Krediet RT. Performance of the Cockcroft-Gault, MDRD, and new CKD-EPI formulas in relation to GFR, age, and body size. Clin J Am Soc Nephrol. 2010;5(6):1003-9.

6. Zhang L, Wang F, Wang $L$, et al. Prevalence of chronic kidney disease in China: a cross-sectional survey. Lancet (London, England). 2012;379(9818):815-22.

7. Cai Q, Mukku VK, Ahmad M. Coronary artery disease in patients with chronic kidney disease: a clinical update. Curr Cardiol Rev. 2013;9(4):331-9.

8. Lamprea-Montealegre JA, McClelland RL, Grams M, Ouyang P, Szklo M, de Boer $\mathrm{H}$. Coronary heart disease risk associated with the dyslipidaemia of chronic kidney disease. Heart. 2018:104(17):1455-60.

9. Reiss $A B$, Miyawaki N, Moon J, et al. CKD, arterial calcification, atherosclerosis and bone health: inter-relationships and controversies. Atherosclerosis. 2018. 278:49-59.

10. Roberts JK, Rao SV, Shaw LK, Gallup DS, Marroquin OC, Patel UD. Comparative efficacy of coronary revascularization procedures for multivessel coronary artery disease in patients with chronic kidney disease. Am J Cardiol. 2017;119(9):1344-51.

11. Charytan DM, Desai M, Mathur M, et al. Reduced risk of myocardial infarct and revascularization following coronary artery bypass grafting compared with percutaneous coronary intervention in patients with chronic kidney disease. Kidney Int. 2016;90(2):411-21.

12. Charytan DM, Natwick T, Solid CA, Li S, Gong T, Herzog CA. Comparative effectiveness of medical therapy, percutaneous revascularization, and surgical coronary revascularization in cardiovascular risk subgroups of patients with CKD: a retrospective cohort study of medicare beneficiaries. Am J Kidney Dis. 2019;74(4):463-73.

13. Kang SH, Lee CW, Yun SC, et al. Coronary artery bypass grafting vs. drugeluting stent implantation for multivessel disease in patients with chronic kidney disease. Korean Circ J. 2017:47(3):354-60.

14. Wang Y, Zhu S, Gao P, Zhang Q. Comparison of coronary artery bypass grafting and drug-eluting stents in patients with chronic kidney disease and multivessel disease: a meta-analysis. Eur J Intern Med. 2017:43:28-35.

15. Farkouh ME, Sidhu MS, Brooks MM, et al. Impact of chronic kidney disease on outcomes of myocardial revascularization in patients with diabetes. J Am Coll Cardiol. 2019;73(4):400-11.

16. Lamy A, Devereaux PJ, Prabhakaran D, et al. Off-pump or on-pump coronary-artery bypass grafting at 30 days. N Engl J Med. 2012;366(16): 1489-97.

17. Garg AX, Kurz A, Sessler DI, et al. Perioperative aspirin and clonidine and risk of acute kidney injury: a randomized clinical trial. JAMA. 2014;312(21):2254-64.

18. Ueki $\mathrm{C}$, Miyata $\mathrm{H}$, Motomura $\mathrm{N}$, et al. Off-pump technique reduces surgical mortality after elective coronary artery bypass grafting in patients with preoperative renal failure. J Thorac Cardiovasc Surg. 2018:156(3):976-83.

19. LaPar DJ, Rich JB, Isbell JM, et al. Preoperative renal function predicts hospital costs and length of stay in coronary artery bypass grafting. Ann Thorac Surg. 2016;101(2):606-12 discussion 612.

20. Cooper WA, O'Brien SM, Thourani VH, et al. Impact of renal dysfunction on outcomes of coronary artery bypass surgery: results from the Society of Thoracic Surgeons National Adult Cardiac Database. Circulation. 2006;113(8): 1063-70.

21. Hillis GS, Croal BL, Buchan KG, et al. Renal function and outcome from coronary artery bypass grafting: impact on mortality after a 2.3-year followup. Circulation. 2006;113(8):1056-62.

22. Gelsomino S, Del Pace S, Parise $O$, et al. Impact of renal function impairment assessed by CKD (EPI) estimated glomerular filtration rate on early and late outcomes after coronary artery bypass grafting. Int J Cardiol. 2017;227:778-87.

23. Charytan DM, Yang SS, McGurk S, Rawn J. Long and short-term outcomes following coronary artery bypass grafting in patients with and without chronic kidney disease. Nephrol Dial Transplant. 2010;25(11):3654-63.

24. Horowitz B, Miskulin D, Zager P. Epidemiology of hypertension in CKD. Adv Chronic Kidney Dis. 2015;22(2):88-95.

25. Cook JR, Dillie KS, Hakeem A, Bhatti S, Chang SM. Effectiveness of anemia and chronic kidney disease as predictors for presence and severity of coronary artery disease in patients undergoing stress myocardial perfusion study. Am J Cardiol. 2008;102(3):266-71.

26. Sezai A, Hata M, Niino T, et al. Results of low-dose human atrial natriuretic peptide infusion in nondialysis patients with chronic kidney disease undergoing coronary artery bypass grafting: the NU-HIT (Nihon University working group study of low-dose HANP Infusion Therapy during cardiac surgery) trial for CKD. J Am Coll Cardiol. 2011;58(9):897-903.

\section{Publisher's Note}

Springer Nature remains neutral with regard to jurisdictional claims in published maps and institutional affiliations.
Ready to submit your research? Choose BMC and benefit from:

- fast, convenient online submission

- thorough peer review by experienced researchers in your field

- rapid publication on acceptance

- support for research data, including large and complex data types

- gold Open Access which fosters wider collaboration and increased citations

- maximum visibility for your research: over $100 \mathrm{M}$ website views per year

At BMC, research is always in progress.

Learn more biomedcentral.com/submissions 